\title{
Impregnação inadvertida da cápsula posterior do cristalino com azul de tripano durante a facectomia extracapsular: relato de caso
}

\author{
Unintentional staining of lens posterior capsule with trypan blue during \\ extracapsular cataract extraction: case report
}

\author{
Frederico França Marques ${ }^{1}$ \\ Fábio Medaglia Soccol ${ }^{2}$ \\ Daniela M. V.Marques ${ }^{3}$ \\ José Ricardo C. L. Rehder ${ }^{4}$
}

${ }^{1}$ Pós-graduando nível Doutorado pela Universidade Federal de São Paulo - UNIFESP - São Paulo (SP) Brasil.

${ }^{2}$ Médico Residente do Departamento de Oftalmologia da Faculdade de Medicina do ABC - Santo André (SP) - Brasil.

${ }^{3}$ Pós-graduanda nível Doutorado pela UNIFESP - São Paulo (SP) - Brasil.

${ }^{4}$ Chefe do Departamento de Oftalmologia da Faculdade de Medicina do ABC - Santo André (SP) - Brasil.

Endereço para correspondência: Frederico França Marques. Rua Arapá, 28 - Apto. 31 - São Paulo (SP) CEP 04363-060

E-mail: fredani2010@terra.com.br

Recebido para publicação em 20.02.2004

Versão revisada recebida em 20.05.2005

Aprovação em 15.08.2005

\section{RESUMO}

Relato de complicação relacionada ao uso do azul de tripano $0,1 \%$ ocorrida ao corar a cápsula anterior do cristalino em facectomia extracapsular com implante de lente intra-ocular. O corante foi injetado sob alta pressão utilizando a técnica de bolha de ar ocasionando a migração deste através da zônula e conseqüente perda do reflexo vermelho no peroperatório dificultando os passos subseqüentes à extração da catarata e comprometendo temporariamente a acuidade visual no pós-operatório. Tendo como objetivo evitar esta complicação, os autores descrevem ainda, o uso da "Técnica de bolha de ar modificada" no qual o viscoelástico dispersivo é injetado no espaço iridolenticular $360^{\circ}$ para compor uma barreira de proteção.

Descritores: Extração de catarata; Azul tripano/uso diagnóstico; Azul tripano/efeitos adversos; Capsulorrexe; Implante de lente intra-ocular; Complicações intra-operatórias; Relatos de casos [tipo de publicação]

\section{INTRODUÇÃO}

A utilização de corantes capsulares é atualmente preferida por muitos cirurgiões ao realizar a capsulotomia circular contínua (CCC) quando a catarata impossibilita a visão do reflexo vermelho ou mesmo para aqueles cirurgiões em fase de treinamento ${ }^{(1)}$. Diferentes corantes têm sido descritos, dentre eles, fluoresceína sódica $(2 \%)^{(2)}$, hemocoloração com sangue autólogo ${ }^{(3)}$, violeta genciana $(0,1 \%)^{(4)}$, indocianina verde $(0,5 \%)^{(5)}$ e azul de tripano $(0,1 \%)^{(6)}$. O corante mais utilizado é o azul de tripano pois proporciona um elevado grau de contraste aliado à baixa toxicidade endotelial e ser economicamente viável. A despeito do uso de técnica adequada poderão ocorrer complicações que mesmo pouco freqüentes ${ }^{(7)}$ devem ser evitadas.

Nós relatamos neste trabalho uma complicação intra e pós-operatória ocorrida durante a cirurgia de catarata ao utilizar o azul de tripano para corar a cápsula anterior do cristalino através da técnica de bolha de ar, e sugerimos uma nova técnica para evitar esta complicação denominada "Técnica de bolha de ar modificada".

\section{RELATO DE CASO}

O paciente J.L.C., 41 anos, branco, natural de Santo André, apresentouse no setor de catarata da Faculdade de Medicina do ABC referindo piora 
progressiva de acuidade visual em olho direito (OD) há 2,5 anos, negando doença e/ou trauma em sua história, referindo também ser portador de baixa de acuidade visual no olho esquerdo (OE) desde o nascimento.

Ao exame, o paciente apresentava melhor acuidade visual corrigida no olho direito de 20/50 e no olho esquerdo de conta dedos a 0,5 metro. A biomicroscopia do segmento anterior apresentava catarata nuclear 3+/4+ em OD, sem facodonese ou outros sinais de alteração zonular e OE sem alteração. Pressão intra-ocular $14 \mathrm{mmHg}$ em ambos os olhos. O mapeamento de retina em OD embora dificultado pela opacidade de meios, mostrava retina colada e pólo posterior sem alterações; em contra-partida, ao exame do OE, observou-se uma extensa cicatriz de coriorretinite no pólo posterior com aproximadamente $5 \mathrm{~mm}$ de extensão.

Foi indicada para o olho direito a facectomia extra-capsular e implante de lente intra-ocular a ser realizada pelo cirurgião em treinamento (R3). Visando obter uma melhor visão da cápsula anterior do cristalino e conseqüentemente um melhor controle na realização da capsulotomia circular contínua, o cirurgião optou pelo uso do azul de tripano $0,1 \%$.

Após a realização da incisão principal do tipo limbar triplanar com uso de lâmina de bisturi de diamante $3,2 \mathrm{~mm}$, parcialmente aberta (aproximadamente $2 \mathrm{~mm}$ ), o humor aquoso foi substituído por uma bolha de ar injetada através da incisão utilizando uma seringa de insulina e uma cânula de $27 \mathrm{G}$. Em seguida realizou-se a injeção de $0,3 \mathrm{ml}$ do corante com uma seringa de insulina acoplada a uma cânula de $27 \mathrm{G}$. Importante ressaltar que a câmara anterior se manteve estável não havendo saída da bolha de ar pela incisão durante o procedimento. Por fim, a bolha de ar foi trocada pelo viscoelástico dispersivo (Metilcelulose 2\% - Ophthalmos ${ }^{\circledR}$ ) e a capsulotomia circular contínua pode ser realizada utilizando-se uma pinça Utrata, sem complicação com a ajuda do corante capsular.

Após a hidrodissecção, hidrodelineação, rotação do núcleo e sua luxação para a câmara anterior com auxílio de um cistítimo, a incisão foi ampliada para $7 \mathrm{~mm}$, o núcleo extraído utilizando-se alça e gancho, e as massas aspiradas sem intercorrências. Após este procedimento, o cirurgião observou completa perda de reflexo vermelho estando em seu lugar um reflexo azul escuro impossibilitando a localização da borda da capsulorrexis e até mesmo avaliação da integridade da cápsula posterior. Com auxílio de uma espátula iriana projetada gentilmente em direção à cápsula posterior, foi possível constatar sua presença devido às discretas estrias produzidas pelo seu contato com o instrumento, porém a borda da capsulorrexis não era visível, sendo assim, o cirurgião optou por fazer o implante da lente intra-ocular no sulco ciliar obtendo-se boa centração do implante confirmada com uso de miótico intracameral $\left(\right.$ Carbacol $\left.^{\circledR}\right)$, o viscoelástico foi removido e a incisão suturada com 5 pontos simples de Mononylon 10,0.

No 1 dia pós-operatório, o paciente relatava estar com a visão levemente azulada apresentando à biomicroscopia de segmento anterior uma córnea com discreto edema, câmara anterior formada, lente intra-ocular centrada e o reflexo verme- lho encontrava-se azulado, porém não impossibilitando o exame de retina que se apresentava sem alteração.

Na primeira semana pós-operatória, o paciente referia melhora dos sintomas evoluindo à acuidade visual de 20/30 com melhor correção, negando sintomas ou queixas de visão azulada e o reflexo vermelho normal, assim como o mapeamento de retina. No primeiro mês pós-operatório, o paciente manteve este quadro, sem queixas visuais e após o controle do astigmatismo induzido, através da retirada de pontos no meridiano corneano mais curvo realizado no $45^{\circ}$ o dia de pós-operatório, o paciente teve alta no terceiro mês.

\section{DISCUSSÃO}

Capsulotomia circular contínua é um passo fundamental na cirurgia de catarata, especialmente no que se refere à técnica de facoemulsificação. Entretanto, esta técnica de capsulotomia torna-se difícil de ser realizada em casos de catarata branca, catarata "nigrans"(8), ou parcialmente reabsorvida onde a cápsula anterior não é facilmente visualizada decorrente da ausência parcial ou total de reflexo vermelho. Várias recomendações têm sido feitas para compensar a ausência de reflexo vermelho, as quais incluem a diminuição da luz da sala cirúrgica, aumento da magnificação do microscópio, iluminação lateral e viscoelástico de alto peso molecular ${ }^{(8)}$. Entretanto, a solução mais efetiva é realizar a CCC com o auxílio de um corante $^{(9)}$.

Algumas soluções têm sido propostas para efetuar a coloração da cápsula anterior do cristalino como a fluoresceína intracameral subcapsular(2), a hemocoloração com sangue autólogo $^{(3)}$, a violeta genciana ${ }^{(4)}$, a indocianina verde ${ }^{(5)}$, e por fim, o uso do azul de tripano ${ }^{(6)}$.

Existem diferentes técnicas utilizadas para o uso seguro destes corantes. Dentre elas, recomenda-se aspirar o humor aquoso, refazer a câmara anterior com uma bolha de ar, e injetar o azul de tripano entre a bolha e a cápsula anterior do cristalino $^{(6)}$.

Alguns autores relataram algumas desvantagens em relação às técnicas e corantes utilizados para corar a cápsula do cristalino; a fluoresceína pode eventualmente corar a córnea e migrar para a cavidade vítrea devido ao seu baixo peso molecular (376 Daltons) e sua injeção subcapsular também cora o córtex dificultando a distinção entre este e a cápsula anterior do cristalino $^{(9)}$. Já em relação à técnica da bolha de ar, esta pode gerar uma câmara anterior menos estável ao entrar com o instrumento através da incisão além de ser tóxico ao endotélio ${ }^{(10)}$.

Outros autores descreveram uma técnica usando o azul de tripano diluído em hialuronato de sódio sob a bolha de ar para corar a cápsula anterior ${ }^{(11)}$. Arshinof descreveu "The ultimate soft shell technique" compartimentalizando a câmara anterior usando azul de tripano em combinação com HealonV ou I-Visc ao realizar a capsulorrexis em catarata branca, madura ou hipermadura $^{(12)}$. Em 2004, esta técnica foi modificada introduzindo um passo a mais, através da instilação de BSS, visando 
criar um espaço entre o viscoelástico e a cápsula anterior a ser preenchido pelo azul de tripano evitando assim corar o viscoelástico e/ou estruturas adjacentes ${ }^{(13)}$.

No caso apresentado neste trabalho, a perda do reflexo vermelho durante a cirurgia ocorreu devido à migração de azul de tripano através da zônula atingindo o canal de Petit e a membrana hialóide anterior e conseqüentemente a face posterior da cápsula posterior do cristalino. O excesso de azul de tripano injetado combinado à elevação desproporcional da pressão na câmara anterior causada pela bolha de ar foram provavelmente os fatores determinantes do extravasamento do corante. $\mathrm{O}$ azul de tripano também é utilizado em procedimentos de retina e vítreo porém em concentrações inferiores $(0,06 \%)$ para evitar toxicidade de estruturas adjacentes ${ }^{(14)}$. Embora tenha ocorrido intensa impregnação per-operatória o vítreo foi poupado e a recuperação visual foi abreviada.

Uma dificuldade presente nestes casos é avaliar a integridade da cápsula posterior, uma vez que não temos a presença do reflexo vermelho. Esta pode ser avaliada pressionando gentilmente um instrumento rombo (espátula de íris) contra a cápsula posterior para evidenciar suas estrias, e menos eficientemente, devido à falta de reflexo vermelho, através da injeção de viscoelástico procurando avaliar a distensão do saco capsular.

Como alternativa para evitar tal complicação, especialmente em pacientes com área zonular comprometida, descrevemos uma técnica denominada "Técnica de bolha de ar modificada", aonde inicialmente, através da paracentese, injeta-se viscoelástico dispersivo entre a superfície posterior da íris e a cápsula anterior do cristalino $360^{\circ}$ procurando criar uma barreira, em seguida, através da incisão principal, injeta-se uma bolha de ar no centro da câmara anterior com conseqüente saída do humor aquoso. Devido à sua característica dispersiva o viscoelástico tende a ficar no local inicial ou deslocar-se centralmente pelo gradiente de pressão negativo ocorrido geralmente no momento desta troca, porém com o aumento da pressão intracameral pela bolha de ar este viscoelástico é novamente deslocado posteriormente situando-se entre a íris e a região zonular anterior criando assim, uma barreira desejada de proteção á passagem do corante devendo ser este injetado pela paracentese para manter a integridade da incisão principal e maior estabilidade da câmara anterior.

Os corantes capsulares são ótimas opções em casos onde o reflexo vermelho está ausente, entretanto, o seu uso não está isento de complicações como demonstrado neste trabalho. A impregnação inadvertida da cápsula posterior do cristalino pelo azul de tripano foi uma complicação encontrada devido ao desconhecimento de sua possível ocorrência. Baseado neste desconhecimento, desenvolvemos a "Técnica de bolha de ar modificada" que proporciona um maior controle na aplicação do corante evitando assim sua migração indesejada para a cavidade vítrea especialmente em olhos com alteração zonular prévia, entretanto, um número maior de casos é necessário para melhor confirmamos a eficácia desta técnica.

\section{ABSTRACT}

Report of a complication related to the use of $0.1 \%$ trypan blue during capsular staining of the anterior crystalline lens capsule in an extracapsular cataract extraction with intraocular lens implantation. The capsular dye was injected using an airbubble technique, inadvertently, it was done using high pressure dispersing the dye through the zonules leading to a complete losts of red reflex, the following steps of the procedure becoming more difficult after the cataract extraction and causing a temporary disturbance of visual acuity in the postoperative period. In order to avoid this complication, the authors also describe the use of "Modified air-bubble technique" where dispersive viscoelastic is placed into the iridolenticular space $360^{\circ}$ to create a protection barrier.

Keywords: Cataract extraction; Trypan blue/diagnostic use; Trypan blue/adverse effects; Capsulorhexis; Lens implantation, intraocular; Intraoperative complications; Case reports [publication type]

\section{REFERÊNCIAS}

1. Dada T, Ray M, Bhartiya P, Vajpayee RB. Trypan-blue-assisted capsulorhexis for trainee phacoemulsification surgeons. J Cataract Refract Surg. 2002; 28(4):575-6. Comment in: J Cataract Refract Surg. 2003;29(5):861-2.

2. Hoffer KJ, McFarland JE. Intracameral subcapsular fluorescein staining for improved visualization during capsulorhexis in mature cataracts [letter]. J Cataract Refract Surg. 1993;19(4):566.

3. Cimetta DJ, Gatti M, Lobianco G. Haemocoloration of the anterior capsule in white cataract CCC. Eur J Implant Refract Surg. 1995;7:184-5.

4. Prieto I, Cabral J, Roque J, Esperancinha FE. An old colorant for a new technique: capsular staining with gentian violet [video]. In: 16 Congress of the European Society of Cataract and Refractive Surgeons; 1998. Nice, Set. 1998. Available from: http://jmbcabral.planetaclix.pt/trabalhos_4_video.html

5. Horiguchi M, Miyake K, Ohta I, Ito Y. Staining of the lens capsule for circular continuous capsulorrhexis in eyes with white cataract. Arch Ophthalmol. 1998; 116(4):535-7.

6. Melles GR, Waard PW, Pameyer JH, Beekhuis W. Trypan blue capsule staining to visualize the capsulorhexis in cataract surgery. J Cataract Refract Surg. 1999;25(1):7-9.

7. Van Dooren BT, Waard PW, Poort-van Nouhuys H, Beekhuis WH, Melles GR. Corneal endothelial cell density after trypan blue capsule staining in cataract surgery [letter]. J Cataract Refract Surg. 2002;28(4):574-5.

8. Wilbrandt HR. Mini-capsulorhexis for intercapsular phacoemulsification assures intraocular lens centration. Eur J Implant Refract Surg. 1990;2:75-7.

9. Pandey SK, Werner L, Escobar-Gomez M, Roig-Melo EA, Apple DJ. Dyeenhanced cataract surgery. Part 1: anterior capsule staining for capsulorhexis in advanced/white cataract. J Cataract Refract Surg. 2000;26(7):1052-9.

10. Kim EK, Cristol SM, Geroski DH, McCarey BE, Edelhauser HF. Corneal endothelial damage by air bubbles during phacoemulsification. Arch Ophthalmol. 1997;115(1):81-8. Erratum in: Arch Ophthalmol. 1997;115(5):630.

11. Kayikicioglu Ö, Erakgün T, Güler C. Trypan blue mixed with sodium hyaluronate for capsulorhexis. J Cataract Refract Surg. 2001;27(7):970. Comment in: J Cataract Refract Surg. 2003;29(2):237.

12. Arshinoff SA. Using BSS with viscoadaptives in the ultimate soft-shell technique. J Cataract Refract Surg. 2002;28(9):1509-14.

13. Marques DV, Marques FF, Osher RH. A Three-step technique for staining the anterior lens capsule using indocyanine green or trypan blue. J Cataract Refract Surg. 2004;30(1):13-6. Comment in: J Cataract Refract Surg. 2005;31(2):259-60.

14. Perrier M, Sebag M. Trypan blue-assisted peeling of the internal limiting membrane during macular hole surgery. Am J Ophthalmol. 2003;135(6):903-5. Comment in: Am J Ophthalmol. 2004;137(1):207-8; author reply 208. 